\title{
Lubiprostone: evaluation of the newest medication for the treatment of adult women with constipation-predominant irritable bowel syndrome
}

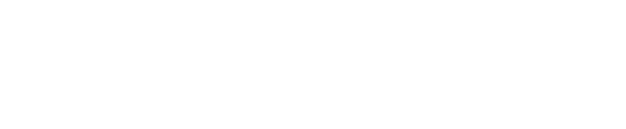

\section{Tisha N Lunsford \\ Lucinda A Harris}

Department of Gastroenterology and Hepatology, Mayo Clinic - School of Medicine, Scottsdale, Arizona, USA
Correspondence: Lucinda A Harris Department of Gastroenterology and Hepatology, Mayo Clinic - School of Medicine, 13400 East Shea Blvd, Scottsdale, AZ 85255, USA

Tel $+|480-30|-6990$

Email harris.lucinda@mayo.edu

\begin{abstract}
Irritable bowel syndrome (IBS) is a chronic disorder that affects primarily female patients and is thought also to afflict approximately $7 \%-10 \%$ of the population of the Western World. Although bowel habits may change over the course of years, patients with IBS are characterized according to their predominant bowel habit, constipation (IBS-C), diarrhea (IBS-D), or mixed type (IBS-M), and treatments are focused toward the predominant symptom. Current treatments for IBS-C have included fiber, antispasmodics, osmotic and stimulant laxatives, and the now severely limited 5-HT 4 agonist tegaserod. No one agent has been universally successful in the treatment of this bothersome syndrome and the search for new agents continues. Lubiprostone (Amitiza ${ }^{\circledR}$ ), a novel compound, is a member of a new class of agents called prostones and was approved for the treatment of chronic idiopathic constipation in 2006 at a dose of $24 \mu \mathrm{g}$ twice daily and then in 2008 for the treatment of IBS-C in women only at a dose of $8 \mu \mathrm{g}$ twice daily. Its purported mechanism is as a type 2 chloride channel activator, but recent evidence suggests that it may also work at the cystic fibrosis transport receptor. This article will compare the newly proposed mechanism of action of this compound to the purported mechanism and review the structure, pharmacology, safety, efficacy, and tolerability of this new therapeutic option. Clinical trial data leading to the approval of this agent for the treatment of IBS-C and the gender-based understanding of IBS, as well as this agent's place among existing and emerging therapies, will be examined.
\end{abstract}

Keywords: large intestine, functional bowel disorder, therapy

\section{Introduction}

Irritable bowel syndrome (IBS) is a chronic condition affecting $7 \%-10 \%$ of the population characterized by abdominal pain or discomfort and is associated with a change in bowel movement form or frequency (or both) that is usually relieved with defecation. ${ }^{1,2}$ It is also not associated with biochemical or structural changes. ${ }^{2}$ The above statement is the definition put forth by the American College of Gastroenterology. However, the Rome Committee has advanced a more complex definition based on stool characteristics and subtype - diarrhea, constipation, mixed, and unsubtyped ${ }^{3}$ (Table 1). By definition, patients with IBS with constipation (IBS-C) should have stools that are hard or lumpy greater than $25 \%$ of the time and loose or mushy less than $25 \%$ of the time. Consistency is defined using the Bristol Stool Scale (Table 1). IBS-C is usually distinguished from chronic idiopathic constipation (CIC) by the presence of abdominal pain. However, in reality, the 2 disorders often overlap in the same individual. ${ }^{4}$ 
Table I Definition of IBS - American College of Gastroenterology and Rome III definition with Bristol Stool Form Scale

\begin{tabular}{|c|c|}
\hline American College of Gastroenterology & Rome III definition \\
\hline Abdominal pain or discomfort associated with altered bowel & I. IBS with constipation (IBS-C) - hard or lumpy stools ${ }^{*} \geq 25 \%$ \\
\hline \multirow[t]{7}{*}{ function without evidence of biochemical or structural abnormality. } & and loose (mushy) or watery stools ${ }^{\dagger}<25 \%$ of bowel movements. ${ }^{\ddagger}$ \\
\hline & 2. IBS with diarrhea (IBS-D) - loose (mushy) or watery stools ${ }^{\dagger} \geq 25 \%$ \\
\hline & and hard or lumpy stool ${ }^{*}<25 \%$ of bowel movements. ${ }^{\ddagger}$ \\
\hline & 3. Mixed IBS (IBS-M) - hard or lumpy stools ${ }^{*} \geq 25 \%$ and loose (mushy) \\
\hline & or watery stools ${ }^{\dagger} \geq 25 \%$ of bowel movements. ${ }^{\ddagger}$ \\
\hline & 4. Unsubtyped IBS (IBS-U) - insufficient abnormality of stool consistency \\
\hline & to meet criteria IBS-C, D or $\mathrm{M}^{\ddagger}$ \\
\hline
\end{tabular}

"Bristol Stool Form Scale I-2 [separate hard lumps like nuts (difficult to pass) or sausage shaped but lumpy]; 'Bristol Stool Form Scale 6-7 (fluffy pieces with ragged edges, a mushy stool or watery, no solid pieces, entirely liquid); $\neq_{\text {In }}$ the absence of use of antidiarrheals or laxatives. ${ }^{* *+}$ Criteria must have been present for at least 3 days out of the past 3 months and have an onset $>6$ months before diagnosis.

\begin{tabular}{ll}
\hline The Bristol Stool Form Scale & \\
\hline Type & Description \\
\hline I. & Separate hard lumps like nuts (difficult to pass) \\
2. & Sausage shaped but lumpy \\
3. & Like sausage but with cracks on its surface \\
4. & Like sausage or snake, smooth and soft \\
5. & Soft blobs with clear cut edges (passed easily) \\
6. & Fluffy pieces with ragged edges, a mushy stool \\
7. & Watery, no solid pieces, entirely liquid \\
\hline
\end{tabular}

It is important to recognize that sufferers with IBS may have constipation, diarrhea, or an alternating bowel habit associated with pain and bloating that frequently characterizes acute flares of chronic symptomatology. Studies have consistently shown that there is a greater prevalence of IBS in women in Western countries (2-3 female: 1 male) and that women have a statistically significant greater prevalence of IBS-C. ${ }^{1,5,6}$ Women also tend to seek medical help more readily than men, further magnifying the gender differences. ${ }^{7,8}$ In a US population where IBS is responsible for $12 \%$ of primary care visits and up to $28 \%$ of all gastroenterology visits, it is apparent that IBS and, specifically, IBS-C are responsible for a significant health care burden and should be of specific concern for those practitioners specializing in women's health. ${ }^{9-12}$

With the exception of the now severely therapeutically limited 5- $\mathrm{HT}_{4}$ agonist tegaserod, treatment options for patients with IBS-C have essentially centered on currently available treatments used for occasional and chronic constipations often with unsatisfactory results. Frequently, studies evaluating most of the currently available agents have been of poor quality and uncertain efficacy. Indeed, studies have demonstrated that both physicians and patients have been dissatisfied with the results of existing therapies for the treatment of chronic constipation. ${ }^{13,14}$ Since the therapies are similar for both IBS-C and CIC, it is not difficult to infer that clinician satisfaction for currently available IBS therapies is equally unsatisfactory, and survey data from patients indicate that $99 \%$ of patients have tried traditional agents. ${ }^{14}$ This article will review the therapeutic challenges of treating IBS that led to the development of the novel therapy lubiprostone (Amitiza ${ }^{\circledR}$; Sucampo Pharma Americas, Inc., Bethesda, MD, USA and Takeda Pharmaceuticals America, Inc., Deerfield, IL, USA. Amitiza ${ }^{\circledR}$ is a registered trademark of Sucampo Pharmaceuticals. Inc.). ${ }^{15,16}$ In addition, the structure, pharmacology, safety, efficacy, and tolerability of lubiprostone will be examined, and the newly reported mechanism of action of this agent on the cystic fibrosis transmembrane conductance regulator $(\mathrm{CFTR})^{17}$ in comparison with its proposed mechanism of action on the type 2 chloride channel (ClC-2) is discussed. The clinical trials data that led to the approval of this agent for the treatment of IBS-C and the gender-based understanding of IBS will be examined. IBS factors influencing the utilization of this medication, as well as the place of this agent among existing and emerging therapies, will also be discussed.

\section{Therapeutic challenges in treating IBS-C}

The high prevalence, economic burden, and elusive pathophysiology of disorder have resulted in a slow but steady impetus for research into effective treatments for IBS, but the course has been rather tumultuous. Drug companies have been searching for treatment options that would relieve the manifold symptoms of IBS sufferers. Traditional 
options targeted at the predominant bothersome complaint have offered incomplete relief. In IBS-C, patients can suffer from mild to severe constipation, as well as from abdominal discomfort or pain often compounded by abdominal bloating, feelings of incomplete evacuation, flatus, psychological distress, and a decreased quality of life (QoL). ${ }^{18,19}$

Traditional recommendations for the treatment of IBS-C have usually centered on beginning with lifestyle recommendations, such as increasing fluids, exercise, and managing stress. Common treatments for constipation, such as increased dietary fiber, are often unsuccessful in patients with IBS-C as they may exacerbate the accompanying complaints of bloating and flatus. Other treatments targeting constipation in the setting of IBS have included bulking agents (isphagula husk), osmotic laxatives (including lactulose and PEG 3350), and tegaserod, a $5-\mathrm{HT}_{4}$ partial agonist. Of these agents, only tegaserod has been judged by a panel of gastroenterologists to have strong evidence, ie, high-quality, randomized, controlled trials that demonstrate not only the goal of increasing spontaneous bowel movements (SBMs) but also the goal of achieving the overall improvement in global symptom relief and satisfaction with defecation in female patients with IBS-C. ${ }^{20,21}$ However, concerns regarding cardiovascular safety resulted in the drug being removed from the market in March 2007, when examination of the total clinical trial database revealed a higher incidence of cardiovascular events (unstable angina, myocardial infarction, and cerebrovascular events) in the tegaserodtreated group compared with the placebo-treated group. Currently, this drug is only available from the US Food and Drug Administration (FDA) through an emergency investigational new drug protocol. The complicated market experience of serotonergic drugs (with alosetron for IBS-D being placed in a restricted use program and the tegaserod experience for IBS-C as described previously) have forced the pharmaceutical industry to look at other receptor sites in the gastrointestinal tract. Research into epithelial function has led scientists to look at chloride channels. These channels among other functions manage fluid secretion in the gut and this has resulted in the development of a new class of agents for the treatment of constipation called prostones. Lubiprostone was approved in 2006 at a dose of $24 \mu \mathrm{g}$ twice daily for the treatment of chronic constipation in men and women. In April 2008, this drug at a dose of $8 \mu \mathrm{g}$ twice daily became the only approved medication by the FDA for treatment of female patients with IBS-C. ${ }^{22,23}$

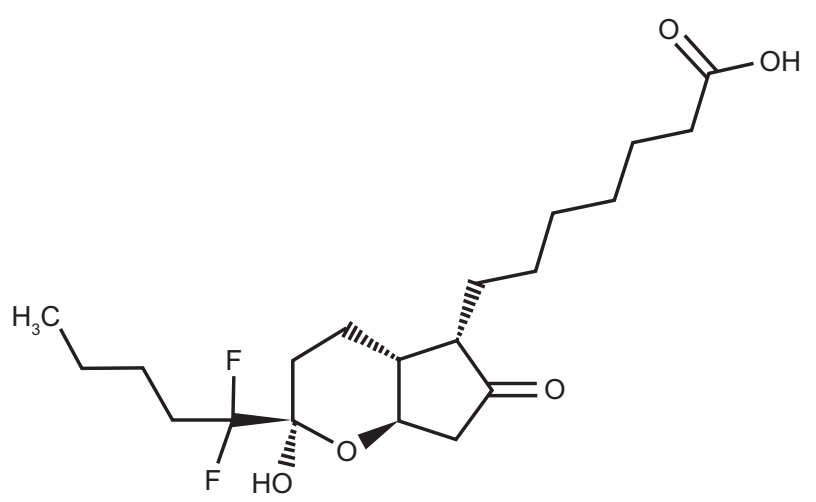

Figure I Chemical structure of lubiprostone (RU-02II) $\left(\mathrm{C}_{20} \mathrm{H}_{32} \mathrm{~F}_{2} \mathrm{O}_{5}\right)$.

Note: Drug bank: accession number DB0 I046; CAS registry number I36790-76-6.

\section{Pharmacology of lubiprostone Structure}

Lubiprostone is classified as a prostone, a bicyclic fatty acid, previously known as difluoropentyl-2-hydroxy-6oxooctahydrocyclopenta-heptanoic acid. ${ }^{24}$ It is derived from prostaglandin E1 and is described as a colorless powder that is insoluble in water but soluble in ethanol. Chemically, it can tautomerize between 2 different forms, the active form of lubiprostone is illustrated in Figure 1.

\section{Metabolism and pharmacokinetics}

Many commonly used drugs, such as proton pump inhibitors, rely on the cytochrome P450 system for their metabolism. But, this is not the case for lubiprostone. Animal studies have shown lubiprostone is metabolized within the gastrointestinal tract, particularly in the stomach and the jejunum, by the microsomal carbonyl reductase system. Ninety-four percent of the drug is bound to plasma proteins. There is an active metabolite, M3, which unlike the parent compound is systemically absorbed. The half-life of this metabolite is estimated to be $0.9-1.4$ hours. Large population studies have not been performed, but gender did not seem to influence the metabolism of this drug. The metabolite, M3, is the compound that was used to estimate the area under the curve (AUC), maximum plasma concentration $\left(\mathrm{C}_{\max }\right)$, and half-life $\left(\mathrm{t}_{1 / 2}\right)$ values based on a $24-\mu \mathrm{g}$ dose of the drug since systemic absorption of the drug itself is severely limited. Peak plasma levels of M3, after a single oral dose with $24 \mu \mathrm{g}$ of lubiprostone, occurred at approximately 1.10 hours. The $\mathrm{C}_{\max }$ was $41.5 \mathrm{pg} / \mathrm{mL}$, and the mean $\mathrm{AUC}_{0-\mathrm{t}}$ was $57.1 \mathrm{pg} \cdot \mathrm{hr} / \mathrm{mL}$. The $\mathrm{AUC}_{0-\mathrm{t}}$ of $\mathrm{M} 3$ increased the dose proportionally after ingestion of single 24- and $144-\mu \mathrm{g}$ doses of lubiprostone. Unfortunately, the metabolism of the drug in patients with renal and hepatic failure has not been tested..$^{25}$ 
Information on pharmacokinetic data of lubiprostone is derived from the drug's package insert because this has not been independently evaluated. ${ }^{24}$ From 0.25 to 168 hours after the initial dose administration, blood samples were obtained to test for serum levels of lubiprostone concentration. The plasma levels were all below $10 \mathrm{pg} / \mathrm{mL}$, ie, all were virtually in negligible concentrations, demonstrating a low systemic bioavailability after oral administration of the drug. Data on food effect have been evaluated using a $72-\mu \mathrm{g}$ dose of the drug, and when given with food, the $\mathrm{C}_{\text {max }}$ was decreased by $55 \%$. However, $\mathrm{AUC}_{0-\infty}$ was unchanged when lubiprostone was given with a fatty meal. The clinical importance of the effect of meals on drug pharmacokinetics is not clear, but the drug was administered with food and water during most of the clinical trials. Elimination studies performed with a radio-labeled, $72-\mu \mathrm{g}$ dose of drug demonstrate that $60 \%$ of the radioactivity is eliminated within 24 hours in the urine and $30 \%$ of the radioactivity is recovered in the stool within 168 hours. Only negligible amounts of the drug and its active metabolite are traceable in the stool.

\section{Pharmacodynamics}

Pharmacodynamic response of lubiprostone has been assessed by Camilleri and colleagues. ${ }^{26}$ They found by measuring the frequency and characteristics of bowel movements following multiple doses of the drug that the maximum-tolerated effective dose for daily treatment was $24 \mu \mathrm{g}$ thrice daily. Higher doses increased the side effects but not the pharmacodynamic effect. This study also evaluated the effect of lubiprostone on gastrointestinal transit, and gastric sensory and motor functions with orally administered lubiprostone ( $24 \mu \mathrm{g}$ twice daily) in 30 normal individuals. When compared with placebo, lubiprostone reduced gastric emptying but accelerated small bowel and colonic transits. All segments of the colon exhibited the propulsive effects of lubiprostone, and in addition, fasting gastric volume was found to increase but this did not have any significant effect on postprandial gastric volume.

Although there does not appear to be gender-related differences in metabolism, recent data from a randomized, double-blind, placebo-controlled, single-center, parallel-group, pharmacodynamic study of lubiprostone in healthy volunteers found that there are significant gender differences in colonic compliance and postprandial colonic tone. ${ }^{27}$

All patients received either $24 \mu \mathrm{g}$ of lubiprostone or placebo. Using barostat-manometry that was endoscopically placed, treatment effects on colonic sensation and motility were measured. The drug was found to reduce postprandial colonic tone (likely responsible for relief of constipation), and although not statistically significant, lubiprostone did increase the pain sensation thresholds from colonic barostat distention in women treated with lubiprostone. The mechanism for the gender differences remains unclear; however, it is hypothesized that it may have to do with the effect of sex hormones on type 2 chloride (ClC-2) channels. It was also found that lubiprostone did not increase the colonic motor function, but it was found that the decrease in colonic compliance and tone would facilitate laxation.

\section{Mechanism of action}

Thus far, 9 types of chloride channels are known to exist. ${ }^{28}$ The most recognized member of this family is the CFTR, which is a cyclic adenosine monophosphate (cAMP)-dependent chloride channel, located on the intestinal epithelium is believed to be activated by protein kinase A-mediated phosphorylation. This chloride channel is known to handle a major portion of apical chloride transport in the intestine, but other chloride channels are also active. ${ }^{29}$

Other volume-regulated chloride channels that have been described in liver and gastrointestinal cells of both mammalian and nonmammalian cells are the type 2 and type 3 chloride channels (ClC-2 and $\mathrm{ClC}-3$ ). A variety of actions, including intracellular $\mathrm{pH}$ regulation, epithelial $\mathrm{Cl}^{-}$transport and fluid secretion, exocytosis, maintenance of the membrane potential, transmembrane transport of organic osmolytes, and cell proliferation, have been purported to be performed by these cells. According to the scientific literature, ClC-2 channels have been found on small and large intestinal epithelial cells, as well as on gastrointestinal parietal cells.

In 2004, lubiprostone (SPI-0211, RU-0211), a bicyclic fatty acid, was reported to activate apical ClC-2, but not CFTR channels on transfected human cells. ${ }^{30}$ As noted, this novel agent was derived from prostaglandin E1 and is a member of a class of drugs known as prostones. ${ }^{31}$ However, these prostones, unlike prostaglandins, are not believed to stimulate smooth muscle contraction. The postulated mechanism of action is that the active secretion of chloride from the epithelial ClC-2 channel into the lumen is followed by the passive paracellular secretion of sodium (down the electrochemical gradient) and water, which resulted in isotonic fluid in the intestinal lumen increasing the liquidity of the intestinal contents. This secretion of fluid is then believed to promote increased intestinal transit, perhaps by stimulation of local stretch receptors resulting in smooth muscle stimulation (Figure 2). ${ }^{26,32}$ 


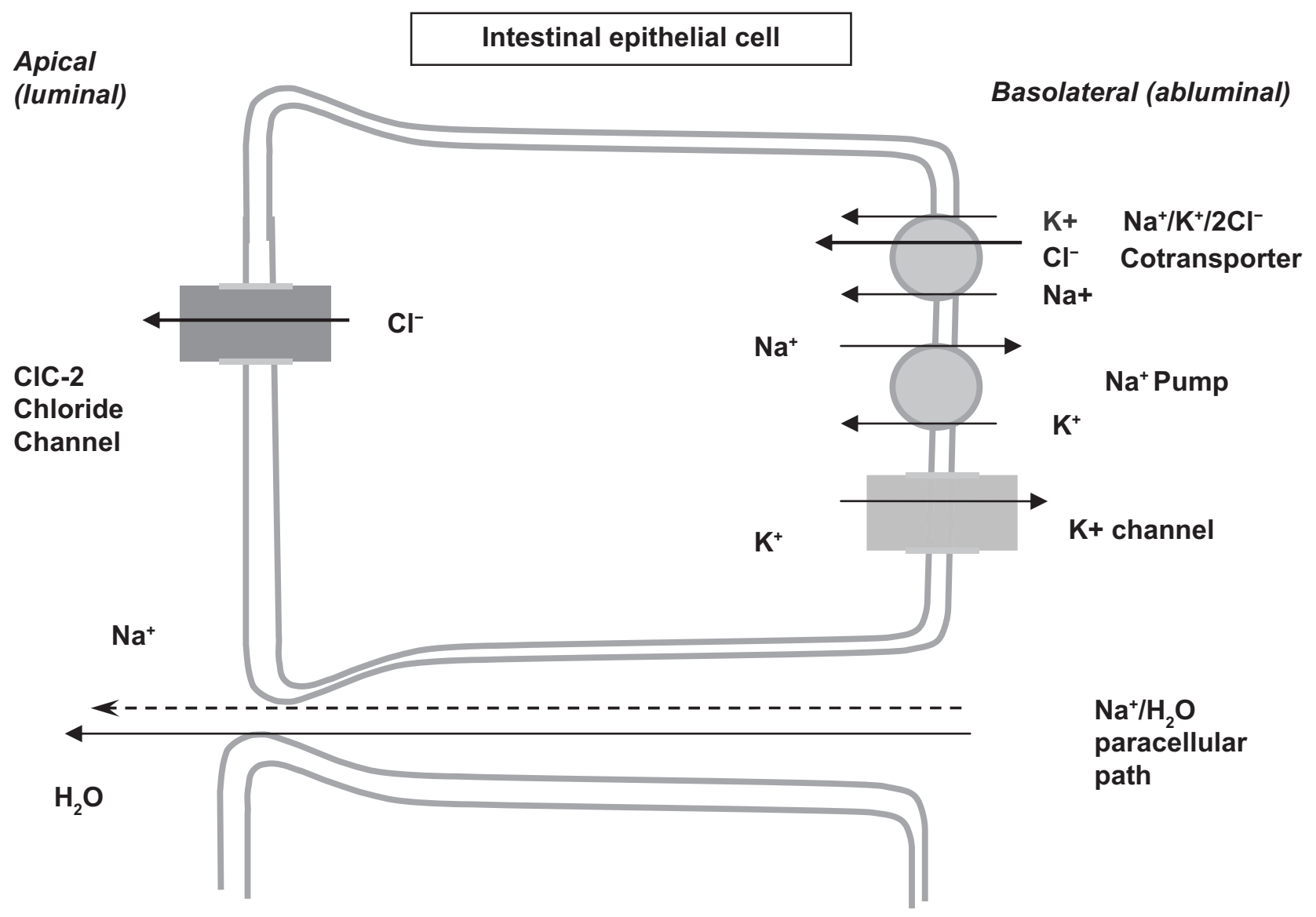

Figure 2 Mechanism of action of lubiprostone across the intestinal epithelial cell. Copyright @2004. Adapted with permission from American Physiological Society. Cuppoletti J, Malinowska DH,Tewari KP, et al. SPI-02II activates T84 cell chloride transport and recombinant human CIC-2 chloride currents. Am J Physiol Cell Physiol. 2004;287(5):CI I73CII83.

Abbreviations: $\mathrm{Cl}^{-}$, chloride; $\mathrm{H}_{2} \mathrm{O}$, water; $\mathrm{K}^{+}$, potassium; $\mathrm{Na}^{+}$, sodium; $\mathrm{ClC}-2$, type 2 chloride channel.

Lubiprostone is believed to work by opening the chloride channels in the small and large intestines, as well as by opening bicarbonate $\left(\mathrm{HCO}_{3}^{-}\right)$secretory pathways in the duodenum. Controversy exists as to which chloride channels are stimulated: the CFTR or the ClC-2 channel. Additional controversy also exists as to whether the drug might directly stimulate smooth muscle through prostaglandin receptors (ie, a G-protein-coupled cAMP signal transduction pathway) or whether the $\mathrm{ClC}-2$ channel is expressed in the apical or basolateral membrane of mucosal epithelial cells.

Addressing the location of the channels, immunofocal microscopy has demonstrated $\mathrm{ClC}-2$ channels on the apical side of human gastrointestinal epithelial cells. ${ }^{30}$ Interestingly, evidence also exists that these $\mathrm{ClC}-2$ channels have been demonstrated on the basolateral membrane of distal colonic epithelial cells in guinea pigs ${ }^{33}$ and in the vicinity of tight junctions. ${ }^{34}$ The explanation that $\mathrm{ClC}-2$ channels exist on both sides of epithelial cells has been that the basolateral channel may serve as an exit pathway for $\mathrm{Cl}^{-}$in the distal colon. It has also been suggested that chloride channels on both surfaces of the epithelial cells might provide a cross talk mechanism to match fluxes at the apical and basolateral domains. However, if ClC-2 channels were to exist only on the basolateral side of the membrane, then ClC-2 - mediated chloride transport would actually lower the electrochemical potential driving chloride extrusion across the apical membrane and so would be a major issue in view of its therapeutic implications for treatment of CIC and IBS-C as discussed previously.

It appears that the differences in the effect of lubiprostone may lie in the differences in the biophysical properties of the 2 different chloride channels, as well as the differences in the concentrations of drug, used in different studies and hence the seemingly contradictory results. First, chloride channels in 2 types of epithelial cell lines were investigated: T84 cells (human-transfected adenocarcinoma cell line) and A6 cells (distal nephron cell line of an African frog, Xenopus laevis). ${ }^{35,36}$ Patch-clamp 
recordings looking at anion flux in both of these cell lines revealed that the $\mathrm{ClC}-2$ channels were inwardly rectifying the channels that were activated by membrane hyperpolariztion. On the other hand, CFTR channels were outwardly rectifying $\mathrm{Cl}^{-}$channels. This led to the conclusion by Bao et $\mathrm{al}^{36}$ that $\mathrm{ClC}-2$ channels were ideally suited for aiding anion secretion with minimal anion absorption while CFTR channels could make either resorption or secretion possible depending on the anion gradient. ${ }^{36}$

Experiments on chloride secretion either in T84 monolayers or in whole-cell patch-clamp studies using a cell line transfected with human ClC-2 channels have demonstrated that lubiprostone stimulates $\mathrm{Cl}^{-}$secretion. ${ }^{17,30}$ In fact, Cuppoletti et $\mathrm{al}^{30}$ found that the half-maximal effective concentration $\left(\mathrm{EC}_{50}\right)$ of lubiprostone required to stimulate chloride secretion in the $\mathrm{ClC}-2$ channels in the transfected cells was $17 \mathrm{nmol} / \mathrm{L}$ and $18 \mathrm{nmol} / \mathrm{L}$ in the T84 cells. Bijvelds et al ${ }^{17}$ reported that the $\mathrm{EC}_{50}$ for $\mathrm{T} 84$ cells was higher and in the micromolar range. The experiments of $\mathrm{Bao}$ et $\mathrm{al}^{36}$ explained this controversy by reporting that concentrations of less than $100 \mathrm{nmol} / \mathrm{L}$ activated $\mathrm{ClC}-2$ channels in the xenopus kidney cells (A6 cells) and concentrations greater than $100 \mathrm{nmol} / \mathrm{L}$ activated the CFTR channel in the same monolayers suggesting at least an explanation for the dichotomy. ${ }^{36}$

A series of other experiments with forskolin (a chloride channel stimulator) using protein kinase A inhibitors ${ }^{17,37,38}$ and tetrotoxin (a toxin that blocks enteric nerve function) indicated that the action of lubiprostone is directly on the chloride channel and is independent of a secondary chemical messenger (eg, cAMP) or secretomotor function of enteric neurons.

There has also been conjecture about the site of action of the drug related to the fact that lubiprostone is a derivative of prostaglandin E1, and therefore, structurally similar to prostaglandins. Therefore, it has been theorized that the drug might directly stimulate smooth muscle through prostaglandin receptors (ie, a G-protein-coupled cAMP signal transduction pathway). Results from 3 different models (T84 cell monolayers, gastric smooth muscle strips, and duodenal loops in situ) are used as evidence supporting a mechanism of action linked to prostaglandin receptors..$^{17,39,40}$ However, animal studies on a guinea pig model have not demonstrated that the drug has a direct stimulatory effect on gastrointestinal smooth muscles..$^{40,41}$ In fact, Cuppoletti et al studied cultured human uterine smooth muscle cell and found that lubiprostone acted in a fashion directly opposite to that of prostaglandins E1 and E2. The drug decreased calcium levels, did not change cAMP levels, and caused hyperpolarization rather than depolarization of muscle cells. ${ }^{41}$ Recently, Bassil et al ${ }^{40}$ demonstrated that though the drug caused contraction of stomach longitudinal muscle cells in rat and human, it inhibited electrical field-stimulated contractions of colonic circular smooth muscle cells. In fact, a prostaglandin EP1 receptor antagonist blocked the stimulatory effects of lubiprostone on longitudinal muscle, whereas the inhibition of circular smooth muscle was reduced by a prostaglandin EP4 antagonist. Despite this study, the majority of evidence from the Cuppoletti study argues against lubiprostone action being mediated by EP receptors. ${ }^{41}$ In addition, the fact that tetrodotoxin, a neurotoxin, fails to suppress the secretory response of lubiprostone are inconsistent with this agent having a prostaglandin-like excitatory action on secretomotor neurons.

Currently, it appears that the weight of the evidence favors that the action of the drug is via the ClC-2 channel, but this controversy points to the need for further research regarding the role of its influence on CFTR channels, as well as on G-protein-coupled prostaglandin receptors. Also, since mucosal inflammation may play a role in the pathophysiology of IBS, data on file with Sucampo/Takeda have demonstrated that activation of $\mathrm{ClC}-2$ by lubiprostone has been shown to stimulate recovery of mucosal barrier function via the restoration of tight junction protein complexes in ex vivo studies of ischemic porcine intestine. ${ }^{24}$ However, the role of tight junctions in IBS-C is unclear. ${ }^{24}$

\section{Safety and tolerability}

As discussed previously, lubiprostone is poorly absorbed from the intestinal tract resulting in a reduced potential for systemic toxicity, as well as limited availability. The clinical trials for both chronic constipation and IBS listed nausea, diarrhea, and headache as the most common side effects of the drug. ${ }^{24}$ Not surprisingly, the percentages of patients reporting these and other side effects were substantially reduced at the lower dose of $8 \mu \mathrm{g}$ twice daily compared with the larger dose of $24 \mu \mathrm{g}$ twice daily (Table 2). The main side effect appears to be nausea and no really good explanation exists for this side effect. However, fluid shifts within the gut have been postulated to be a possible cause. ${ }^{26}$

Despite the fact that the drug can cause diarrhea, clinical trials did not reveal any significant changes in electrolyte levels. Pooled results from both open-label and double-blind trials for chronic constipation, ie, at a dose of $24 \mu \mathrm{g}$ twice daily, did not indicate any significant changes in electrolytes over a treatment period of $12-48$ weeks. ${ }^{42}$ The percentage of patients aged 65 years or older was $10.5 \%$ and $18.6 \%$, respectively, in the 2 groups of trials. 
Table 2 Safety profile of lubiprostone compared in chronic constipation and IBS-C in phase II and phase III trials

\begin{tabular}{|c|c|c|c|c|}
\hline Symptom & $\begin{array}{l}\text { Placebo *C } \\
N=346(\%)\end{array}$ & $\begin{array}{l}\text { Lubiprostone } 24 \mu \mathrm{g} \\
\text { twice daily } N=1 \text { I | } 3 \text { (\%) }\end{array}$ & $\begin{array}{l}\text { Placebo **IBS } \\
\mathbf{N}=435 \text { (\%) }\end{array}$ & $\begin{array}{l}\text { Lubiprostone } 8 \mu \mathrm{g} \\
\text { twice daily } \mathrm{N}=10 \mathrm{I} \text { I } \\
\text { (\%) }\end{array}$ \\
\hline Nausea & $16(5.1)$ & $346(31.1)$ & $17(4)$ & $81(8)$ \\
\hline Diarrhea & $3(0.9)$ & $147(13.2)$ & $17(4)$ & $71(7)$ \\
\hline Headache & $21(6.6)$ & 147 (I3.2) & No reported & Not reported \\
\hline Abdominal distention & $9(2.2)$ & $79(7.1)$ & $22(5)$ & $50(5)$ \\
\hline Abdominal pain & $7(2.8)$ & $75(6.7)$ & $9(2)$ & $30(3)$ \\
\hline Flatulence & $6(1.9)$ & $68(6.1)$ & Not reported & Not reported \\
\hline Vomiting & $3(0.9)$ & $5 I(4.6)$ & Not reported & Not reported \\
\hline Dizziness & $4(1.3)$ & $46(4.1)$ & Not reported & Not reported \\
\hline
\end{tabular}

Electrocardiogram (EKG) changes have not been reported in the clinical trials with this drug either in patients with constipation $(\mathrm{n}=177)$ or in healthy male and female controls $(n=68)$ (ages not reported). ${ }^{43}$ EKG changes were recorded either after a single $24-\mu \mathrm{g}$ dose or after a supratherapeutic $144-\mu \mathrm{g}$ dose and did not show any changes.

Lubiprostone is metabolized by carbonyl reductase and not by the cytochrome P450 system confirming its low likelihood of drug - drug interactions. ${ }^{24}$ Postmarketing data have essentially supported this claim with few additional side effects being reported. It is not approved for individuals younger than 18 years, and there is no clinically available data on patients with hepatic or renal impairment. ${ }^{24}$

Dyspnea is also an important but infrequent side effect that can occur. It has been reported in the clinical trials in $2.5 \%$ of the treated patients with CIC and in $0.4 \%$ of the treated patients with IBS-C. Although this was not classified as a serious adverse event, some patients discontinued treatment because of dyspnea. The dyspnea was described by patients as a sensation of chest tightness and difficulty in taking in a breath, generally with an acute onset within 30-60 minutes after taking the first dose. Postmarketing reports of dyspnea have also been reported when lubiprostone was used at a dose of $24 \mu \mathrm{g}$. Although $\mathrm{ClC}-2$ channels exist in respiratory epithelium, the mechanism by which dyspnea occurs is not known. In vitro experiments conducted on respiratory epithelial tissue, where the drug is applied topically, suggest that the drug can activate chloride secretion but do not shed any light on this side effect. ${ }^{44,45}$ Further, it is difficult to postulate how lubiprostone might affect the respiratory epithelium in humans who take the drug orally when only minuscule amounts are absorbed and even smaller amounts of the active metabolite are available. This symptom generally resolved within a few hours after patients took the dose of medication, but subsequent doses of the drug have caused recurrence of the dyspnea. Therefore, patients should be cautioned not to take the medication again until evaluated by a clinician.

\section{Special populations Pregnant and lactating women}

This drug is classified as pregnancy class $\mathrm{C}$ because of its possible association with fetal loss in a single-animal study. ${ }^{24}$ Why this occurred is not fully understood and is also postulated to have to do with fluid shifts within the body. During the preclinical phase of development, rats and mice exposed to supratherapeutic doses of lubiprostone did not demonstrate any teratogenic effects or other toxicities. However, when guinea pigs were exposed to the higher doses, 2 guinea pigs developed intrauterine loss. Studies in humans have not been performed, but during the clinical testing, 6 women became pregnant while on the drug, and per protocol, the drug was discontinued. ${ }^{24}$ Four women had normal deliveries, and the fifth woman was progressing as expected without adverse events but was lost to follow-up. The sixth pregnancy was electively terminated. Although there has been no evidence of toxicity in human fetuses till date, it is advised that lubiprostone only be used during pregnancy "if the potential benefits justify the potential risks to the fetus." ${ }^{24}$ The package insert recommends that women who could become pregnant should have a negative pregnancy test before beginning treatment with the drug and also should be capable of complying with appropriate contraceptive measures. ${ }^{24}$

It is not known whether lubiprostone is secreted into breast milk. Therefore, taking into account the importance of the drug for the mother, it should be recommended to stop either the drug or the breast-feeding. ${ }^{24}$

\section{Children}

The drug is not recommended or approved in patients younger than 18 years of age. 
Studies in children are currently underway, but this drug is not yet FDA approved for the treatment of chronic constipation or IBS-C in children.

\section{Geriatric use}

There is no upper age limit for the use of this medication in elderly female patients with IBS-C. In the clinical trials, the safety profile of lubiprostone in the elderly patients ( $\geq 65$ years of age, $8 \%$ of the population were $\geq 65$ years of age and $1.8 \%$ of the population were $\geq 75$ years of age) was consistent with the safety profile in the overall study population. ${ }^{24}$ There were no sufficient numbers of patients aged 65 years and older to determine whether elderly patients respond differently compared with younger patients.

\section{Hepatic and renal impairment}

Lubiprostone data are not available in patients with hepatic or renal failure.

\section{Gender differences in the pathophysiology of IBS}

Various pathophysiologic mechanisms have been put forth for IBS, including differences in autonomic function, changes in visceral pain perception, immune and inflammatory mediators, and central processing of visceral stimuli. ${ }^{7}$ Research into the gender differences in functional bowel diseases has primarily been evaluated in IBS and the etiology for the female predominance in IBS remains elusive. In addition, most of the data have not been bowel habit specific, but intriguing data supporting possible gender differences in motility were presented in a 2005 study of patients with slow-transit constipation versus controls, which suggested that endocrine or hormonal imbalance might play a role. ${ }^{24,46}$ In this study, colectomy specimens were obtained from women with intractable slow-transit constipation and from women with left colon adenocarcinoma (controls). These samples were analyzed and compared for possible downregulation of contractile $G$ proteins possibly related to overexpression of progesterone receptors. However, there were to be no published nondrug studies that compared colonic motility in men and women with IBS. ${ }^{7}$

Besides changes in motility, it is known that patients with IBS in general have increased visceral perception compared with healthy controls, ${ }^{47,48}$ but few studies have compared the difference in visceral perception between men and women. Two studies have demonstrated that women with IBS have enhanced rectal perception compared with men with IBS. ${ }^{49,50}$
In addition, one study analyzed the effect of the menstrual cycle on visceral perception and found that there may be an effect on rectal sensitivity in women with IBS but not in healthy women. This study examined rectal sensitivity in women with IBS compared with controls across the 4 phases of the menstrual cycle (menses, follicular phase, luteal phase, and premenstrual phase) and demonstrated that perceptual thresholds were lower during menses in patients with IBS compared with their menstrual cycle phase. ${ }^{51}$

In addition, there may be gender differences in the central processing of visceral stimuli. Two neuroimaging studies have found that men and women with IBS did have significant differences in brain response to aversive pelvic visceral stimuli with men showing greater activation of the dorsal anterior cingulate cortex, the lateral prefrontal cortex, and the dorsal pons/periacqueductal gray. These areas seem to be more involved in endogenous pain inhibition as opposed to women with IBS who showed greater activation of the limbic and paralimbic regions, areas more involved with the pain-facilitation circuit and perhaps more associated with emotional response to pain. ${ }^{52,53}$

An area of particular interest in the pathophysiology of IBS is that pharmacotherapy research suggests that genderrelated differences may exist with respect to response to drug therapy. Alosetron, a 5- $\mathrm{HT}_{3}$ antagonist, currently available to treat severe IBS-D, demonstrated a significant improvement in multiple IBS symptoms in women but not in men. ${ }^{54} \mathrm{~A}$ subsequent study restricted to male patients demonstrated significant improvement in IBS pain, discomfort, and stool consistency but not in other IBS symptoms..$^{55}$ Cilansetron, another $5-\mathrm{HT}_{3}$ antagonist for IBS-D that did not make it to the market, demonstrated that although there was an overall significant improvement in men, the response was less robust than in the female patients. ${ }^{56,57}$ Finally, several studies also suggested that the $5-\mathrm{HT}_{4}$ agonist tegaserod may have greater efficacy in female patients. Whether this purely reflects the smaller number of male patients studied or sex differences in serotonin receptors has yet to be determined, but it is an area of interest to be considered when evaluating pharmacologic therapy. ${ }^{60}$

\section{Lubiprostone - efficacy studies Chronic constipation}

Safety and efficacy data on the use of lubiprostone for chronic constipation have been reported in one phase II study and two phase III studies originally published in abstract form. ${ }^{61-63}$ In 2007, the phase II, multicenter, dose-ranging, double-blind, placebo-controlled trial results were published 
in detailed form. ${ }^{64}$ In this study, chronic constipation was defined as fewer than 3 bowel movements per week for 6 months or more, with at least 1 symptom associated with chronic constipation. Of 129 patients enrolled, 127 patients received at least 1 dose of drug and were included in the final analysis. Patients first went through a 14-day washout/run-in period and then were randomized to receive $24 \mu \mathrm{g}$ of lubiprostone once, twice, or thrice daily versus placebo for 3 weeks. Over weeks 1 and 2 of treatment, patients treated with 48 and $72 \mu \mathrm{g} /$ day of therapy had a statistically significant increase in the number of SBMs per week compared with placebo. ${ }^{64}$ SBMs were the primary outcome measure and this was defined as bowel movements not occurring within 24 hours of rescue medication use. During week 3, results were no better with 48 or $72 \mu \mathrm{g} /$ day compared with $24 \mu \mathrm{g} /$ day. Increased adverse events (predominantly nausea) at $72 \mu \mathrm{g} /$ day did not provide a clear risk-to-benefit advantage compared with the $48 \mathrm{mcg} /$ day dosing, hence this dose of $24 \mu \mathrm{g}$ twice daily was chosen for subsequent phase III studies and is the current recommended dose in chronic constipation.

Subsequent studies included 2 identical placebo-controlled trials enrolling 479 (237 and 242, respectively) patients. ${ }^{65,66}$ Both studies enrolled patients symptomatic with CIC, based on modified Rome II criteria, which was defined as fewer than 3 bowel movements per week for greater than or equal to 6 months, with at least 1 symptom associated with idiopathic constipation (hard or very hard stool, incomplete evacuation, and straining with defecation) each for at least $25 \%$ of bowel movements (BMs). ${ }^{67} \mathrm{~A}$ 2-week run-in period preceded a 4-week randomized treatment phase and was followed by a 1-week withdrawal. In both studies, patients were primarily female (approximately $90 \%$ ) and Caucasian (76\%-86\%) and they received either lubiprostone $(24 \mu \mathrm{g})$ or placebo, twice daily. The primary end point was SBM frequency after the initiation of treatment. Over the entire 4-week trial, lubiprostone significantly increased the number of SBMs compared with placebo $(57 \%-63 \%)$ with a similar response rate in male and female patients. Lubiprostone treatment was also associated with significant improvements in stool consistency, straining, and abdominal symptoms ${ }^{68,69}$ Comparable results were also found in the elderly patients. ${ }^{70}$

Long-term, open-label safety and efficacy data from a multicenter trial have also been reported..$^{71}$ A total of 880 patients with chronic constipation were enrolled in the 3 trials and were administered lubiprostone ( $24 \mu \mathrm{g}$, twice daily) for 6 $(n=308)$ to $12(n=572)$ months. Johanson and colleagues ${ }^{71}$ reported continued efficacy for improving the frequency of bowel movements and other constipation-related symptoms.
The average improvement in constipation severity for all the 3 studies was $26 \%$ at weeks $4-6(n=828), 29 \%$ at week 24 $(\mathrm{n}=512)$, and $28 \%$ at week $48(\mathrm{n}=281)$. Lubiprostone was well tolerated, similar to the phase III clinical trials, with nausea being the primary drug-related adverse symptom, reported in $27 \%$ of patients. However, only $6.6 \%$ of patients discontinued the medication. A subanalysis of this data in patients older than 65 years revealed that elderly patients had positive treatment outcomes and tolerated the drug well. ${ }^{70}$ In fact, nausea was less prominent in the elderly population.

Lubiprostone was also revealed to have no rebound effects in a randomized withdrawal study conducted in 128 patients. ${ }^{72}$ Following 4 weeks of lubiprostone treatment $(24 \mathrm{mcg}$ twice daily), patients were randomized to continue active treatment for another 3 weeks or receive placebo. At week 7, consistent efficacy was observed in patients on lubiprostone while those who had been switched to placebo had fewer SBM, but there was no associated rebound effect as SBMs were still improved from baseline. ${ }^{72}$ This lack of rebound effect was also confirmed in a recent abstract by Chey et $\mathrm{al}^{73}$ in patients with IBS-C. They demonstrated that withdrawal of lubiprostone was not associated with symptom rebound following drug discontinuation and there was some suggestion that clinical benefits may extend beyond drug cessation.

\section{IBS-C}

A dose-ranging, double-blind, placebo-controlled study in 195 patients was the first study to evaluate the safety and efficacy of lubiprostone in the treatment of IBS-C. All these patients met Rome III criteria for IBS and were randomized to receive placebo or 1 of 3 different lubiprostone doses $(8,16$, or $24 \mu \mathrm{g}$ twice daily) for 12 weeks after a 4 -week screening period. ${ }^{20}$ Change in abdominal pain/ discomfort during the first 4 weeks of therapy was the primary end point. Secondary end points included abdominal bloating, frequency of SBM, straining at stool, and stool consistency. A variety of parameters was monitored and included IBS-QoL, symptom diaries, laboratory tests, and EKGs. The patients were primarily Caucasians (83\%) and females (92\%). During months 1 and 2, patients showed a greater improvement in mean abdominal pain and discomfort scores $(P=0.023$ and $P=0.39$, respectively) at any dose of lubiprostone compared with placebo. This difference was not seen at month 3 . Even though patients at $24 \mu \mathrm{g}$ twice daily showed the greatest improvement in abdominal pain/discomfort, they also had the greatest number of adverse events. It was concluded that the $8-\mathrm{mcg}$ dose twice daily gave the best combination of safety and 
efficacy. Although IBS-QoL was examined, it was not found to be statistically significant in the lubiprostone group. However, the study was not adequately powered to detect changes in QoL scores.

Two double-blinded, placebo-controlled studies run in parallel led to the approval of lubiprostone by FDA as the only prescription drug therapy for IBS-C in the United States in April 2008 in women 18 years of age or older. ${ }^{74}$ The studies randomized 1,171 patients (92\% women; age range, $18-65$ years) with IBS-C by Rome II criteria to receive $8 \mathrm{mcg}$ of lubiprostone or placebo, twice daily for 12 weeks. The follow-up programs for the studies were slightly different, with 1 study having a 4-week open-label extension. Otherwise, they were identical over the first 12 weeks of treatment. Overall efficacy and safety were evaluated in 1,154 adults who completed the treatment phase of either of the 2 trials. The overall response rate after 12 weeks of treatment was the primary end point. The statistical analysis was combined for the 2 study samples because the initial 12 weeks of the treatment portions were of the same study design and run in parallel. The overall response rate was calculated based on weekly electronic diary data using the patient's response to a global symptom relief question based on a 7-point, balanced Likert symptom relief scale ("significantly worse" to "significantly relieved"): "How would you rate your relief of IBS symptoms (abdominal discomfort/pain, bowel habits, and other IBS symptoms) over the past week compared to how you felt before you entered the study?" These end points represented more rigorous end points than have been applied to previous clinical trials for IBS, and the response rates were quite low for both the placebo and active drug groups. However, combined analyses demonstrated a higher overall response rate in the group of patients receiving lubiprostone than in those who had received placebo (17.9\% vs $10.1 \%)$. Analyzing the data separately showed consistent overall response rates between the 2 trials with $16 \mu \mathrm{g}$ /day of lubiprostone significantly more likely compared with placebo to achieve a significant result. A patient was considered an "overall responder" if the criteria for being designated a "monthly responder" was met in at least 2 of the 3 months of the study. A "monthly responder" was defined as a patient who had reported being "significantly relieved" for at least 2 weeks of the month or at least "moderately relieved" in all 4 weeks of that month. A patient was considered a "nonresponder" if they felt worse, increased rescue medication usage, or discontinued the drug due to lack of efficacy. These stricter standards for determining a responder were thought to be the reason for the low placebo response rate in this study.

Again, lubiprostone was generally well tolerated and the main side effect was nausea ( $8 \%$ drug vs $4 \%$ placebo) and diarrhea ( $6 \%$ drug vs $4 \%$ placebo). In the combined analysis, the overall number needed to treat was approximately 13 . A follow-up, open-label extension study showed that benefits continued or improved at 36 weeks and that treatment with lubiprostone confers long-term efficacy and safety in patients with IBS-C. ${ }^{75}$

To date, there have been no comparison studies with other options for the treatment of IBS-C.

\section{Lubiprostone, IBS symptoms, and QoL}

Overall, lubiprostone has been shown to have significant benefits on global IBS symptoms. ${ }^{75}$ In the two 12-week, phase III, multicenter, double-blind, randomized, placebo-controlled studies of over 1,000 patients ( $92 \%$ female), those receiving lubiprostone for IBS ( $8 \mu \mathrm{g}$ twice daily) were nearly twice as likely to achieve overall response compared with those receiving placebo $(P=0.001)$. Overall response was based on global relief of IBS symptoms of abdominal discomfort/ pain, boating, constipation severity, straining, stool consistency, and overall symptom relief. QoL assessed using the IBS-QOL questionnaire, a validated tool that has 8 subscales: dysphoria, interference with activities, body image, health worry, food avoidance, social reaction, sexual, and relationships, was specifically significantly improved in patients receiving lubiprostone versus placebo. ${ }^{75}$ Lubiprostone also specifically improved stool consistency, abdominal bloating (which highly correlated with improvement in abdominal discomfort), and straining; all a wide range of symptoms that plague the average female sufferer of IBS. ${ }^{76}$

\section{Lubiprostone's place in therapy}

It remains unclear why lubiprostone helps relieve global symptoms of IBS and its mechanism of action remains to be fully elucidated. However, studies are beginning to show the possible role of reduced intestinal permeability in IBS. ${ }^{77}$ Patients with IBS often exhibit abnormal gut permeability and corresponding inflammatory response. ${ }^{78-80}$ These physiologic alterations may contribute to the visceral hypersensitivity that typifies this condition. Other possibilities include a decrease in colonic tonicity and alteration of pain perception.

As the understanding of the pathophysiology of IBS has progressed, research regarding therapies has broadened to 
include other relevant neurotransmitters and hormones. The most promising therapeutic options on the horizon include more new selective serotonergic drugs and guanylate cyclase$\mathrm{C}$ (GC-C) receptor agonists. ${ }^{81}$ The cardiovascular side effects of tegaserod and cisapride have stimulated development of agents that are more selective for $5-\mathrm{HT}_{4}$ and for other serotonergic receptors that might have fewer cardiac effects. Three agents show promise in this area, prucalopride, ATI-7505, and velusetrag, and these agents have been shown to enhance colonic and possibly small bowel motility as well. ${ }^{82}$ Prucalopride has demonstrated efficacy not only for severe CIC in phase IIB and III trials but also for cardiovascular safety in elderly individuals (over $80 \%$ of whom had a history of cardiac disease).$^{83,84}$ None of the 100 elderly constipated patients studied had changes in their EKGs (ie, no QT prolongation) or changes in their Holter data..$^{83,84}$

Chloride channels have proven to be a popular new target and like lubiprostone, the medications linaclotide and guanilib work on this target. ${ }^{81}$ These compounds are GC-C agonists that stimulate the production of cyclic-GMP. In a rat model, linaclotide, orally administered, has been demonstrated to stimulate the secretion of chloride and bicarbonate into the intestinal lumen, thereby increasing intestinal fluid and gastrointestinal transit. ${ }^{85}$ This agent is in phase III trials for both IBS-C and CIC and preliminary results look very promising. Only the data regarding a dose-ranging, placebo-controlled trial regarding CIC have been published, and linaclotide produced rapid and sustained improvement of bowel habits and abdominal symptoms and global relief of symptoms. ${ }^{86}$ It also improved QoL and was associated with few adverse events. ${ }^{86}$ Like lubiprostone, this medication has limited systemic absorption and a low side-effect profile. Guanilib is still in early phase trials and so its efficacy is not known.

Although the future looks promising for the development of new agents for the treatment of IBS-C, the good news is that lubiprostone is here now and appears to be safe. Postmarketing data have not revealed any additional concerns. Side effects, such as nausea (ameliorated with concurrent administration with food), diarrhea, headache, and abdominal pain, may limit its use. Lubiprostone may be a gender-specific drug with greater efficacy in female patients with IBS-C, but the fact that there are fewer males in these studies limits the ability to truly make this determination. From a women's health perspective, caution must be exercised in any female of child-bearing age as the drug is pregnancy class $\mathrm{C}$ and urine pregnancy testing before initiating this drug is recommended in the prescribing information. ${ }^{24}$
Lubiprostone provides a much-needed option in the limited armamentarium of the treatments for IBS-C. Its place in therapy has not been clearly delineated, but if patients have failed conservative interventions, such as dietary changes or bulk-forming agents (fiber supplements and dietary changes) and osmotic laxatives (PEG 3350, magnesium hydroxide, and lactulose), then lubiprostone should be used. It may be necessary in some patients to titrate the dose upward to the FDA approved dose of $24 \mu \mathrm{g}$ twice daily used for chronic constipation or to use an intermediate dose. It should be remembered that at times it is difficult to distinguish between $\mathrm{CIC}$ and IBS-C, and titration must be done with care as the side-effect profile increases as the dose is increased. ${ }^{24}$ Consideration should be given to the fact that conventional interventions often exacerbate concurrent symptoms of IBS, such as bloating.

Clinicians need to consider a variety of factors when making therapeutic choices. The fact that few head-to-head comparison studies with other treatment options for IBS-C have been performed is a challenging problem and one that is not likely to be remedied in the near future. Also, clinicians may give more weight to the effectiveness of traditional agents then warranted. Economic concerns, such as insurance reimbursement, may also influence choice of therapy since many plans consider lubiprostone a tertiary agent and do not approve its use until patients have failed other therapies. Most importantly, clinicians often underestimate the severity of disease in patients. A recent on-line international survey of 1,966 patients with IBS used 2 validated instruments (Functional Bowel Disorder Severity Index and IBS Severity Scoring system) and subjective reporting to assess severity of disease (International Foundation for Functional Gastrointestinal Disorders). This study revealed that $20 \%-55 \%$ (depending on the instrument used; subjective response $-35 \%$ ) of these individuals had severe IBS. ${ }^{87}$ Previous literatures suggested that only $5 \%$ of the patients had severe disease. ${ }^{88}$ Despite the severity of disease in this surveyed population, only about $2 \%$ of patients were taking an IBS-targeted drug for their symptoms ${ }^{87}$ raising the issue that these patients may be undertreated. From the patient perspective, the respondents to this survey indicated that to have an effective treatment and achieve "perfect health," they would be willing to sacrifice 15.1 years of life (approximately $25 \%$ of remaining years). ${ }^{87}$

Another study surveying over 250 patients with IBS found that health utilities score (a measure of health-related quality of life [HRQOL] that ranges between 0 [death] and 1 [perfect health]) was $0.7 .^{89}$ This score is comparable to patients with stage III congestive heart failure and rheumatoid arthritis. ${ }^{89}$ 
This illustrates that clinicians may need to use tools that assess severity of disease in their patients. Patient severity can be better predicted for IBS. A recent study in 750 patients with IBS revealed that there were 6 factors that predicted patient assessed severity of disease independently: (1) abdominal pain rating $(P<0.001)$, $(2)$ belief that "something serious is wrong with body" $(P<0.001)$, (3) straining with defecation $(P=0.001),(4)$ myalgias $(P=0.02),(5)$ urgency with defecation $(P=0.03)$, and $(6)$ bloating $(P=0.05) .{ }^{90}$ Symptoms of abdominal pain, straining at stool, and bloating are symptoms commonly seen in patients with IBS-C, and lubiprostone has demonstrated efficacy in treating these symptoms, as well as in improving QoL. In fact, a review of the data by a panel of gastroenterologists using an evidence-based approach supports the use of lubiprostone as a first-line therapy in the treatment of female patients with IBS-C at a dose of $8 \mu \mathrm{g}$ twice daily. ${ }^{2}$ Thus, it is important for clinicians to better assess severity by assessing symptoms more completely and possibly administering validated severity questionnaires to more successfully use this appropriate and effective treatment.

\section{Disclosures}

Dr Lunsford has no conflicts of interest in this work. Dr Harris has acted as a consultant for Takeda Pharmaceuticals, Salix, Ironwood, Proctor \& Gamble, and Prometheus.

\section{References}

1. Chang L, Heitkemper MM. Gender differences in irritable bowel syndrome. Gastroenterology. 2002;123(5):1686-1701.

2. Brandt LJ, Chey WD, Foxx-Orenstein AE, et al. An evidence-based systematic review on the management of irritable bowel syndrome. Am J Gastroenterol. 2009;104 Suppl 1:S8-S35.

3. Longstreth GF, Thompson WG, Chey WD, Houghton LA, Mearin F, Spiller RC. Functional bowel disorders. Gastroenterology. 2006;130(5): 1480-1491..

4. Drossman D, Li Z, Andruzzi E, et al. U.S, Householder survey of functional gastrointestinal disorders. Prevalence, sociodemography and health impact. Dig Dis Sci. 1993;38(9):1569-1580.

5. Thompson WG, Irvine EJ, Pare P, Ferrazzi S, Rance, L. Functional gastrointestinal disorders in Canada: first population based survey using Rome II criteria with suggestions for improving the questionnaire. Dig Dis Sci. 2002;47(1):225-235.

6. Lee OY, Mayer EA, Schmulson, M, Chang, L, Naliboff B. Gender-related differences in IBS symptoms. Am J Gastroenterol. 2001;96(7):2184-2193.

7. Chang L, Toner BB, Fukodo S, et al. Gender, age, society, culture, and the patient's perspective in the functional gastrointestinal disorders. Gastroenterology. 2006;130(5):1435-1446.

8. Chial HJ, Camilleri M. Gender differences in irritable bowel syndrome. J Gender Specif Med. 2002;5(3):37-45.

9. Sandler RS. Epidemiology of irritable bowel syndrome in the United States. Gastroenterology. 1990;99(2):409-415.

10. Chang L. Review article: epidemiology and quality of life in functional gastrointestinal disorders. Aliment Pharmacol Ther. 2004;20 Suppl 7:S31-S39.
11. Drossman DA, Whitehead WE, Camilleri M. Irritable bowel syndrome: a technical review for practice guideline development. Gastroenterology. 1997;112(6):2120-2137.

12. Nyrop KA, Palsson OS, Levy RL, et al. Costs of health care for irritable bowel syndrome, chronic constipation, functional diarrhea and functional abdominal pain. Aliment Pharmacol Ther. 2007;26(2):237-248.

13. Schiller LR, Dennis E, Toth G. Primary care physicians consider constipation as a severe and bothersome medical condition that negatively impacts patients' lives [abstract 724]. Am J Gastroenterol. 2004;99 Suppl:S234-S235.

14. Lembo A. Irritable bowel syndrome medications side effects survey. J Clin Gastroenterol. 2004;38(9):776-781.

15. Lacy BE, Levy LC. Lubiprostone: a chloride channel activator. J Clin Gastroenterol. 2007;41(4):345-351.

16. Lacy BE, Chey WD. Lubiprostone: chronic constipation and irritable bowel with constipation. Expert Opin Pharmacother. 2009;10(1): $143-152$.

17. Bijvelds MJ, Bot AG, Escher JC, De Jonge HR. Activation of intestinal Cl- secretion by lubiprostone requires the cystic fibrosis transmembrane conductance regulator. Gastroenterology. 2009;137(3):976-985.

18. Chang L, Lacy BE, Quigley EMM, Schoenfeld PS. Emerging diagnostic and treatment strategies for irritable bowel syndrome. Gastroenterol Hepatol. 2008;4(10):1-22.

19. Frank L, Kleinman L, Rentz A, Ciesla G, Kim JJ, Zacker C. Healthrelated quality of life associated with irritable bowel syndrome: comparison with other chronic diseases. Clin Ther. 2002;24(4):674-689.

20. Johanson JF, Drossman DA, Panas R, Wahle A, Ueno R. Clinical trial clinical trial: phase 2 study of lubiprostone for irritable bowel syndrome with constipation. Aliment Pharmacol Ther. 2008;27(8):685-696.

21. Khoshoo V, Armstead C, Landry L. Effect of a laxative with and without tegaserod in adolescents with constipation predominant irritable bowel syndrome. Aliment Pharmacol Ther. 2006:23(1):191-196.

22. Lang, L. The Food and Drug Administration approves lubiprostone for irritable bowel syndrome with constipation. Gastroenterology. 2008;135(1):7.

23. Schiller LR, Camilleri M. Lubiprostone: viewpoints [comment]. Drugs. 2006;66(6):880-881.

24. AMITIZA $^{\circledR}$ (lubiprostone) [package insert]. Bethesda, MD: Sucampo Pharmaceuticals, Inc; 2009.

25. Orr, KK. Lubiprostone: a novel chloride channel activator for the treatment of constipation. Formulary. 2006;41(3):118-129.

26. Camilleri M, Bharucha A, Ueno R, et al. Effect of a selective chloride channel activator, lubiprostone, on gastrointestinal transit, gastric sensory and motor functions in healthy volunteers. Am J Physiol Gastrointest Liver Physiol. 2006;290(5):G942-G947.

27. Sweetser S, Busciglio IA, Camiller M, et al. Effect of a chloride channel activator, lubiprostone, on colonic sensory and motor functions in healthy subjects. Am J Physiol Gastrointest Liver Physiol. 2009;296(2):G295-G301.

28. Lipecka J, Bali M, Thomas J, et al. Distribution of CCl-2 chloride channel in rat and human epithelial tissue. Am J Physiol Cell Physiol. 2002;282(4):C805-C816.

29. Vandewalle A. Expression and function of CLC and cystic fibrosis transmembrane conductance regulator chloride channels in renal epithelial tubule cells pathophysiological implications. Chang Gung Med J. 2007;30(1):17-25.

30. Cuppoletti J, Malinowska DH, Tewari KP, et al. SPI-0211 activates T84 cell chloride transport and recombinant human $\mathrm{ClC}-2$ chloride currents. Am J Physiol Cell Physiol. 2004;287(5):C1173-C1183.

31. Lubiprostone: RU 0211, SPI 0211. Drugs $R$ D. 2005;6: 245-248.

32. Grider JR, Jin JG. Distinct populations of sensory neurons mediate the peristaltic reflex elicited by muscle stretch and mucosal stimulation. J Neurosci. 1994;14 Suppl 5(Pt 1):S2854-S2860. 
33. Catalan M, Niemeyer MI, Cid LP, et al. Basolateral ClC-2 chloride channels in surface colon epithelium: regulation by a direct effect of intracellular chloride. Gastroenterology. 2004;126(4):1104-1114.

34. Gyomorey K, Yeger H, Ackerly C. Expression of the chloride channel ClC-2 in the murine small intestine epithelium. Am J Physiol Cell Physiol. 2000;279(6):C1787-C1794.

35. Fritsch J, Edelman A. Modulation of the hyperpolarization-activated $\mathrm{Cl}^{-}$current in human T84 epithelial cells by phosphorylation. J Physiol. 1996;490(Pt 1):115-128.

36. Bao HF, Li L, Self J, et al. A synthetic prostone activates apical chloride channels in A6 epithelial cells. Am J Physiol Gastrointest Liver Physiol. 2009;295(2):G234-G251.

37. Tewari KP, Malinowska DH, Sherry AM, Cuppoletti J. PKA and arachidonic acid activation of human recombinant $\mathrm{ClC}-2$ chloride channels. Am J Physiol Cell Physiol. 2000;279(1):C40-C50.

38. Fei G, Wang YZ, Liu S, et al. Stimulation of mucosal secretion by lubiprostone (SPI-0211) in guinea pig small intestine and colon Am J Physiol Gastrointest Liver Physiol. 2009;296(4):G823-G832.

39. Mizumori M, Akiba Y, Kaunitz JD. Lupiprostone stimulates duodenal bicarbonate secretion in rats. Dig Dis Sci. 2009;54(10):2063-2069.

40. Bassil AK, Boman RA, Jarvie EM, et al. Activation of prostaglandin EP receptors by lubiprostone in rat and human stomach and colon. Br J Pharmacol. 2008;154(1):126-135.

41. Cuppoletti J, Malinowsk DH, Chakrabarti J, Ueno R. Effects of lubiprostone on human uterine smooth muscle cells. Prostaglandins Other Lipid Mediat. 2008;86(1-4):56-60.

42. Rivera E, Wahle A, Joswick TR, Ueno R. Lubiprostone, a novel type-2 chloride channel (Clc-2) activator, does not affect serum electrolyte balance in elderly and non-elderly patients with chronic idiopathic constipation. Gastroenterology. 2007;132(4 Suppl 2):A191-A192.

43. Sprenger C, Copa A, Morganroth J, et al. Effect of lubiprostone, a unique agent for the treatment of chronic idiopathic constipation on clinical electrocardiogram results. Gastroenterology. 2007;132(4 Suppl 2):A325.

44. MacDonald KD, McKenzie KR, Henderson MJ, et al. Lubiprostone activates non-CFTR-dependent respiratory epithelial chloride secretion in cystic fibrosis Mice. Am J Physiol Lung Cell Mol Physiol. 2008;295(9):L933-L940.

45. Joo NS, Wine JJ, Cuthbert AW. Lubiprostone stimulates secretion from tracheal submucosal glands of sheep, pigs and humans. Am J Physiol Lung Cell Mol Physiol. 2009;296(5):L811-L824.

46. Xiao ZL, Pricolo V, Biancani P, Behar J. Role of progesterone signaling in the Regulation of G-protein levels in female chronic constipation. Gastroenterology. 2005;128(3):667-675.

47. Whitehead WE, Holtkotter B, Enck P, et al. Tolerance for rectosigmoid distention in irritable bowel syndrome. Gastroenterology. 1990;98(4):1187-1192.

48. Munakata J, Naliboff B, Harraf F, et al. Repetitive sigmoid stimulation induces rectal hyperalgesia in patients with irritable bowel syndrome. Gastroenterology. 1997;112(1):55-63.

49. Ragnarrsson G, Hallbook O, Bodemar G. Abdominal symptoms are not related to anorectal function in the irritable bowel syndrome. Scand $J$ Gastroenterol. 1999;34(3):250-258.

50. Chang L, Mayer EA, Labus J, et al. Effect of sex on perception of rectosigmoid stimuli in irritable bowel syndrome. Am J Physiol Regul Integr Comp Physiol. 2006;29(2):R277-R284.

51. Houghton LA, Lea R, Jackson N, Whorwell PU. The menstrual cycle affects rectal sensitivity in patients with irritable bowel syndrome but not healthy volunteers. Gut. 2002;50(4):471-474.

52. Berman S, Munakata J, Naliboff BD, et al. Gender differences in regional brain response to visceral pressure in IBS patients. Eur J Pain. 2000;4(2):157-172.

53. Naliboff BD, Berman S, Chang L, et al. Sex-related differences in IBS patients:central processing of visceral stimuli. Gastroenterology. 2003;124(7):1738-1747.
54. Camilleri, M, Mayer EA, Drossman DA, et al. Improvement in pain and bowel function in female irritable bowel patients with alosetron, a 5-HT 3 receptor antagonist. Aliment Pharmacol Ther. 1999;13(9): 1149-1159.

55. Chang L, Ameen VZ, Dukes GE, McSorley D, Mayer EA. A dose-ranging, phase II study of the efficacy and safety of alosetron hydrochloride (Lotronex) in men with diarrhea-predominant IBS. Am J Gastroenterol. 2005;100(1):115-123.

56. Bradette M, Moennikes H, Carter F, et al. Cilansetron in irritable bowel syndrome with diarrhea predominance (IBS-D). Efficacy and safety in a 6 month study. Gastroenterology. 2004; 126(4 Suppl 2):A42.

57. Coremnans G, Clouse RE, Carter F, Krause, G, Caras S, Steinborm C. Cilansetron, a novel 5- $\mathrm{HT}_{3}$ antagonist, demonstrated efficacy in males with irritable bowel syndrome with diarrhea predominance (IBS-D). Gastroenterology. 2004;126(4 Suppl 2):A643.

58. Muller-Lissner SA, Fumagalli I, Bardhan KD, et al. Tegaserod, a 5HT (4) receptor partial agonist, relieves symptoms in irritable bowel syndrome patients with abdominal pain, bloating and constipation. Aliment Pharmacol Ther. 2001;15(10):1655-1666.

59. Kellow J, Lee OY, Chang FY, et al. An Asia-Pacific, double-blind, placebo controlled randomized study to evaluate the efficacy, safety and tolerability of tegaserod in patients with irritable bowel syndrome. Gut. 2003;52(5):671-676.

60. Camilleri M, Atanasova E, Carlson PJ, et al. Serotonin-transporter polymorphism pharmacogenetics in diarrhea-predominant irritable bowel syndrome. Gastroenterology. 2002;123(2):425-432.

61. Johanson JF, Gargano MA, Patchen ML, Ueno R. Efficacy and safety of a novel compound, RU-0211, for the treatment of constipation. Gastroenterology. 2002;122(1 Suppl 4):A315.

62. Johanson JF, Gargano MA, Patchen ML, Ueno R. Phase III efficacy and safety of RU-0211, a novel chloride channel activator, for the treatment of constipation. Gastroenterology. 2003;124(4 Suppl 1):A48.

63. Johanson JF, Gargano MA, Patchen ML, Ueno R. Phase III study of lubiprostone, a chloride channel-2 (CIC-2) activator for treatment of constipation: Safety and primary efficacy. Am J Gastroenterol. 2005; 100(9 Suppl 9s):S328.

64. Johanson JF, Ueno R. Lubiprostone, a locally acting chloride channel activator, in adult patients with chronic constipation: a double-blind, placebo-controlled, dose-ranging study to evaluate efficacy and safety. Aliment Pharmacol Ther. 2007;25(11):1351-1361.

65. Barish CF, Drossman D, Johanson JF, Ueno R. Efficacy and safety of lubiprostone in chronic constipation. Dig Dis Sci. 2010;55(4):1090-1097.

66. Johanson JF, Morton D, Geenen J, Ueno R. Multi-center, 4-week, double-blind, randomized, placebo-controlled trial of lubiprostone, a locally-acting type- 2 chloride channel activator in patients with chronic constipation. Am J Gastroenterol. 2008;103(1):170-177.

67. Thompson WG, Longstreth G, Drossman DA, Heaton K, Irvine EJ, Muller-Lissner S. Functional bowel disorders and functional abdominal pain. In: Drossman DA, Corazziari E, Talley NJ, Thompson WG, Whitehead WE, editors. Rome II: The Functional Gastrointestinal Disorders. McLean VA: Dagnon Associates, Inc; 2000:351-432.

68. Anonymous. Lubiprostone (amitiza) for chronic constipation. Med Lett Drugs Ther. 2006;48(1236):47-48.

69. Johanson JF, Gargano MA, Holland PC, Patchen ML, Ueno R. Phase III efficacy and safety of RU-0211, a novel chloride channel activator, for the treatment of constipation. Gastroenterology. 2003; 124(4 Suppl 1):A104.

70. Ueno R, Panas R, Wahle A, Zhu Y, Holland PC. Long-term safety and efficacy of lubiprostone for the treatment of chronic constipation in elderly subjects. Gastroenterology. 2006; 130(4 Suppl 2):A188.

71. Johanson JF, Gargano MA, Patchen ML, Ueno R. Multi-center open label study of lubiprostone for the treatment of chronic constipation. Am J Gastroenterol. 2005;100(9 Suppl 9):S331. 
72. Johanson JF, Gargano MA, Patchen ML, Ueno R. Phase III, randomized withdrawal study of RU-0211, a novel chloride channel activator for the treatment of constipation. Gastroenterology. 2004; 126(4 Suppl 2):S100

73. Chey WD, Saad RJ, Panas R, Wahle A, Ueno R. Discontinuation of lubiprostone treatment for irritable bowel syndrome with constipation is not associated with symptom increase or recurrence: results from a randomized withdrawal study. Gastroenterology. 2008; 134(4 Suppl 1):A401.

74. Drossman DA, Chey WD, Johanson JF, et al. Clinical trial: lubiprostone in patients with constipation-associated irritable bowel syndrome - results of two randomized, placebo-controlled studies. Aliment Pharmacol Ther. 2009;29(3):329-341.

75. Drossman DA, Chey WD, Scott C, Panas R, Ueno R. Health-related quality of life in adults with irritable bowel syndrome with constipation: results of combined analysis of two phase 3 studies with lubiprostone. Gastroenterology. 2008;134(4 Suppl 1):A469.

76. Chey WD, Drossman DA, Scott C, Panas R, Ueno R. What symptoms drive global symptom improvement with lubiprostone in patients with irritable bowel syndrome and constipation: data from two multicenter, randomized, placebo-controlled trials. Gastroenterology. 2008;134(4 Suppl 1):A28.

77. Camilleri M, Gorman H. Intestinal permeability and IBS. Neurogastroenterol Motil. 2007;19(7):545-552.

78. Dunlop SP, Hepben J, Campbell E, et al. Abnormal intestinal permeability in subgroups of diarrhea-predominant irritable bowel syndrome. Am J Gastroenterol. 2006;101(6):1288-1204.

79. Marshall JK, Thabane M, Garg AX, Clark W, Medings J, Collins SM. Intestinal permeability in patients with irritable bowel syndrome after a waterborne outbreak of acute gastroenteritis in Walkerton, Ontario. Aliment Pharmacol Ther. 2004;20(11-12):1317-1322.

80. Spiller RC, Jenkins D, Thornley JP, et al. Increased rectal mucosal enteroendocrine cells, T lymphocytes, and increased gut permeability following acute Campylobacter enteritis and in post-dysenteric irritable bowel syndrome. Gut. 2000;47(5):804-811.
81. Crowell MD, Harris LA, Lunsford TN, DiBaise J. Emerging drugs for chronic constipation. Expert Opin Emerg Drugs. 2009;14(3): 493-504.

82. Camilleri M. Review article: new receptor targets for medical therapy in irritable bowel syndrome. Aliment Pharmacol Ther. 2010;31(1):35-46.

83. Camilleri M, Kerstens R, Beyens G, Robinson P, Vandeplassche L. A double-blind, placebo controlled trial to evaluate the safety and tolerability of prucalo-pride oral solution in constipated elderly patients living in a nursing facility. Gastroenterology. 2009; 136 Suppl 1:S240.

84. Camilleri M, Beyens G, Kertsens R, Vandeplassche L. Long-term follow up of safety and satisfaction with bowel function in response to oral prucalopride in patients with chronic constipation. Gastroenterology. 2009;136 Suppl 1:S160.

85. Forte LR Jr. Uroguanylin and guanylin peptides: pharmacology and experimental and therapeutics. Pharmacol Ther. 2004;104(2):137-162.

86. Lembo AJ, Kurtz CB, Macdougall JE, et al. Efficacy of linaclotide for patients with chronic constipation. Gastroenterology. 2010;138(3):886-895.

87. Drossman DA, Morris CB, Schneck S, et al. International survey of patients with IBS: symptom features and their severity, health status treatments, and risk taking to achieve clinical benefit. J Clin Gastroenterol. 2009;43(6):541-550.

88. Drossman DA, Thompson WG. The irritable bowel syndrome: review and a graduated multicomponent treatment approach. Ann Intern Med. 1992;116(12 Pt 1):1009-1016.

89. Spiegel B, Harris LA, Lucak S, et al. Developing valid and reliable health utilities in irritable bowel syndrome: results from the IBS PROOF cohort. Am J Gastroenterol. 2009;104(8):1984-1991.

90. Spiegel B, Strickland A, Naliboff BD, Mayer EA, Chang L. Predictors of patient-assessed illness severity in irritable bowel syndrome. Am J Gastroenterol. 2008;103(10):2536-2543.
International Journal of Women's Health

\section{Publish your work in this journal}

The International Journal of Women's Health is an international, peerreviewed open-access journal publishing original research, reports, reviews and commentaries on all aspects of women's healthcare including gynecology, obstetrics, and breast cancer. Subject areas include: Chronic conditions (migraine headaches, arthritis, osteoporosis);

\section{Dovepress}

Endocrine and autoimmune syndromes; Sexual and reproductive health; Psychological and psychosocial conditions. The manuscript management system is completely online and includes a very quick and fair peer-review system. Visit http://www.dovepress.com/ testimonials.php to read real quotes from published authors. 